\title{
EXPERIÊNCIA DAS COMPRAS: UM DIÁLOGO ENTRE ESPAÇOS COMERCIAIS DE NATAL E AS COMPRAS FEMININAS
}

\author{
Adara Pereira da Silva ${ }^{1}$
}

O presente artigo trata de uma reflexão sobre as relações sociais produzida através das compras femininas de roupas, acessórios e maquiagens em três espaços comercias de Natal: O Natal Shopping e os comércios de rua do Centro, Alecrim. Para tanto, faremos um diálogo entre as principais características e particularidades de cada um dos espaços comerciais, a relação construída pelas mulheres com estes espaços e suas estratégias de compras.

Esta reflexão é fruto de uma etnografia iniciada em $2017^{2}$. Comecei a engendrar a pesquisa a partir de algumas vivências e percepções pessoais, enquanto moradora de Natal. Primeiramente percebia, como graduanda da UFRN que as pessoas associavam o uso das roupas a determinado espaço dentro do próprio campus universitário, isto é, se um aluno se vestia de determinada maneira consequentemente era associado ao algum setor do campus ${ }^{3}$. Neste sentido, comecei a refletir se o uso de roupas, algo tão trivial, poderia se revelar como um elemento que compõe um determinado espaço ou mesmo revelar outros aspectos como gosto, classe social, pertencimento.

Segundamente, minha própria experiência enquanto consumidora me fez refletir sobre as compras e os espaços comerciais. Sempre fui fascinada pelo universo da moda e maquiagem, porém, minhas compras de roupas se limitavam às lojas de departamento, pois considerava que estas lojas apresentavam preços acessíveis e produtos de qualidade. Esta limitação era motivada por uma ideia preconcebida: as roupas e maquiagens de comércios de rua, como o Alecrim e Centro, mesmo sendo baratas eram

\footnotetext{
${ }^{1}$ Universidade Federal do Rio Grande do Norte, Brasil. Email: adaraps2@gmail.com ORCID id: https://orcid.org/0000-0003-1294-3535

${ }^{2}$ A pesquisa foi iniciada em 2017 com o trabalho de monografia, da graduação em Ciências Sociais (UFRN), orientado pela Profa. Dra. Eliane Tânia Martins de Freitas. Em seguida, a temática das compras femininas no Alecrim, Centro e Natal Shopping associadas ao uso de redes sociais tornou-se objeto de estudo da minha pesquisa de mestrado (PPGAS-UFRN), também orientada pela Profa. Tânia Freitas, que segue em desenvolvimento.

${ }^{3}$ Os alunos que usavam branco eram associados ao setor de ciências biológicas, já alunos que utilizavam camisas da UFRN, com mochilas, tênis esportivos, bermudas ou calças jeans eram associados ao setor 3, correspondente ao setor de ciências exatas, entre outras associações.
} 
feias e de má qualidade. Este preconceito partia de um imaginário proveniente do meu círculo social. Com o tempo minha visão se modificou, ao encontrar uma loja no Centro com preços baixos e boa qualidade, esta mudança me levou a pensar em como se construiu o imaginário (que não era só meu) em relação aos comércios de rua. Mais uma vez havia uma associação das roupas com o espaço. Nesta equação qualidade $x$ preço pensei que também poderia haver um imaginário, por parte das consumidoras natalenses, que associava os preços altos a boa qualidade.

Então, ao pensar a pesquisa de forma prática (para além das minha próprias percepções e vivências) busquei fazer um comparativo entre comércios de rua, do Centro e do Alecrim e o Natal Shopping. Iniciei o campo buscando entender quais as motivações das compras femininas, com o objetivo de comprovar este pressuposto inicial: que as mulheres viam as peças do Alecrim, e Centro como inferiores, em qualidade, em relação às peças do Natal Shopping, devido ao preço mais baixo.

Para este campo contatei, inicialmente, quatro interlocutoras (no período de desenvolvimento da monografia), realizei entrevistas, pessoalmente e pelo Whatsapp $^{4}$, e acompanhei suas compras pelos espaços. Neste primeiro momento pude constatar que para as entrevistadas a variável preço, de fato, estava relacionada com a variável qualidade, contudo, a primeira não necessariamente determinava a segunda, portanto, para elas seria possível encontrar itens de qualidade e preços baixos no Centro ou Alecrim, como o inverso também seria possível, comprar itens de qualidade inferior no Natal Shopping. Simultaneamente, me deparei com outras questões: justificativas e estratégias de compras, uso da internet para compras, classificação quanto o uso das roupas $^{5}$, relacionamento com os espaços, foram alguns das variáveis evidenciados nesta fase da pesquisa. Por conseguinte, pude constatar que a relação entre os espaços e as compras femininas orquestram diversas relações sociais que não se resumem a preços altos ou baixos.

A partir destas questões dei continuidade a pesquisa encontrando novas variáveis e aprofundando as anteriores. Neste momento, contatei novas interlocutoras, totalizando dez mulheres. Do mesmo modo, realizei entrevistas e acompanhei suas compras. À medida que fui analisando suas falas, senti uma maior necessidade de pensar os

\footnotetext{
${ }^{4}$ Whatsapp é um aplicativo de mensagens instantâneas.

${ }^{5}$ As interlocutoras separavam suas roupas por categorias, como trabalho, festa, praia, cinema, faculdade, desta forma o uso da roupa estava associado ao espaço.
} 
elementos espaciais de cada comércio, que estavam a todo momento estavam em diálogo com o que era apresentado pelas interlocutoras.

Então, realizei algumas caminhadas sistemáticas, para tanto me apoiei no conceito proposto por Magnani (2008), no qual a prática etnográfica é uma forma de operar que supõe a utilização de quadros teóricos mais amplos, isto é, para a etnografia é necessária a alternância em dois níveis: o conhecimento de variáveis abrangentes e o trabalho com significados em nível local. Para realizar uma etnografia no espaço urbano, o autor propõe uma identificação de pontos no espaço em relação a práticas, como também caminhadas de reconhecimento por áreas delimitadas pelos equipamentos e esboços do mapeamento de roteiros, fronteiras e pontos de ligação com outras áreas. Com isso é possível estabelecer um quadro geral, consequentemente, é possível fazer uma descrição do cenário, atores e regras. $\mathrm{O}$ olhar durante a caminhada não deve ser como o de um passeio descompromissado, por outro lado não deve ser apressado. $O$ pesquisador em sua caminhada de reconhecimento deve ter um plano estabelecimento previamente, o qual permita uma observação contínua seguindo um fluxo de andar e parar, uma caminhada sistemática, deixando-se impregnar de estímulos sensoriais, mas buscando a regularidade daquele cenário.

Delimitar o cenário significa identificar marcos, reconhecer divisas, anotar pontos de intersecção - a partir não apenas da presença ou ausência de equipamentos e estruturas físicas, mas desses elementos em relação com a prática cotidiana daqueles que de uma forma ou outra usam o espaço: os atores. Com relação a estes trata-se de detectar tipos, construir categorias, determinar comportamentos agrupando, separando, classificando. Serão moradores, clientes, trabalhadores, passeantes, usuários, transeuntes, manifestantes [...] (Magnani, 2008: 37)

Neste sentido, a caminhada foi muito importante para o reconhecimento dos três cenários: Alecrim, Centro e Natal Shopping. Assim, a caminhada permitiu treinar o olhar para uma realidade que inicialmente é familiar e perceber elementos já vistos anteriormente em uma nova perspectiva e conotação, em diálogo com os trajetos e compras realizadas pelas interlocutoras.

Juntamente, considerando a relação entre pontos no espaço e práticas dos atores, proposta pelo autor, tenciono pensar as compras e os espaços comerciais como planos de investigação concomitantes e conectados. Não faz sentido pensá-los separados, já que não é possível fazer compras em algum dos espaços em sem considerar sua configuração, como também é inviável pensar os espaços fora do contexto das compras, visto que são espaços comerciais. 
Aqui, não estou considerando o consumo numa perspectiva meramente utilitária, impessoal ou como apenas um aspecto da produção. Nas ciências sociais o consumo é caracterizado desta forma, devido a posição superior que o trabalho ocupa na sociedade, por isso os teóricos, durante um longo período, priorizaram análises sobre as relações sociais produzidas pela produção em detrimento das relações produzidas pelo consumo.

Porém, o consumo é um dos elementos que constroem e dão sentido a realidade. Mary Douglas e Baron Isherwood (1996) propuseram que o consumo é uma área de comportamento demarcada por diversas regras que não são impostas nem pelo comércio, nem por uso da força. Os bens são imprescindíveis, são responsáveis por estabelecer e mediar as relações sociais. O consumo, portanto, deve estar inserido dentro do processo social, como uma necessidade social de se relacionar com outras pessoas e possuir aparelhos que mediam esta relação. Estes aparelhos podem ser de diversos tipos, como comidas, bebida, roupas que podem demarcar semelhanças ou diferenças. Desta forma os bens aparecem como contribuição para a vida racional.

Entender o consumo somente como uma criação mercadológica anula as relações sociais criadas por este, seu papel no meio cultural e no próprio contexto da cidade. Eunice Duhram (1986) teorizou sobre o campo o urbano no Brasil, para a autora não havia possibilidade desenvolver uma antropologia urbana no país nos moldes estabelecidos pela escola de Chicago, isto é, seria impraticável tentar compreender o fenômeno urbano em si mesmo. Consequentemente, a cidade é o lugar de investigação e não o seu objeto. Ainda de acordo com Duhram, conforme citado por Cornelia Eckert e Ana Luiza Carvalho da Rocha (2009), a antropologia enfrentava outro problema ao utilizar a teoria marxista, de ordem econômica, para responder questões de ordem cultural e simbólica, já que seu foco são problemas macroestruturais das sociedades capitalista, que só podem ser captadas numa dimensão histórica. A cidade, como complexidade, um lugar de transformação a ser interpretado não poderia ser explicada nesta chave analítica.

De forma semelhante, Magnani propôs que a cidade, sob a ótica de algumas perspectivas, é uma resultante de forças econômicas transnacionais, elites locais, interesses imobiliários ou variações demográficas, uma entidade separada de seus atores. Em outro ponto de vista, a dinâmica da cidade corresponderia apenas ao sistema capitalista, no qual este sistema é uma variável independente "uma dimensão explicativa 
última e total" (Magnani, 2002: 12). Destarte, os atores sociais seriam apenas representantes do capital e de forças mercadológicas. Nesta explicação os moradores da cidade, suas redes, práticas, deslocamentos, estilo de vida são ocultados, todavia "há uma gama de práticas que não são visíveis na chave de leitura política” (Magnani, 2002: $15)$.

Nesta perspectiva, o consumo, enquanto prática que faz parte dos processos que constituem o espaço urbano, não pode ser explicado apenas por teorias econômicas que invisibilizam as relações sociais por ele produzidas. Ponderando tais proposições, neste trabalho analisaremos o consumo de roupas, acessórios e maquiagens como uma prática dos atores no contexto da cidade. Para isso, o trabalho está dividido em duas seções: a primeira apresenta características gerais dos comércios do Alecrim e Centro e do Natal Shopping e suas especificidades. Este primeiro panorama nos ajudará a pensar a assimilação das interlocutoras perante a configuração destes espaços. Na segunda seção, apresentarei as interlocutoras, o relacionamento que elas desenvolveram os espaços comerciais, através das compras e algumas situações e falas, em caráter ilustrativo. Baseado nestes aspectos apontaremos como algumas estratégias de compras são criadas a partir do diálogo entre os espaços comerciais e as compras destas mulheres.

\section{Os espaços e suas particularidades}

\section{Alecrim}

O Alecrim é famoso pelo seu comércio, um dos maiores da cidade, segundo dados da Prefeitura de Natal, no ano de 2006 apresentava 3968 estabelecimentos, dentre eles 921 (23,21\%) eram de serviços em geral e 2712 (68,35\%) eram comércio. Tantos os serviços, quanto o comércio são os mais variados. O Alecrim tem avenidas que são conhecidas tanto por nomenclatura, quanto por números. No comércio são vendidos os mais diversos tipos de mercadorias, populares por seus baixos preços e variedade. Numa mesma calçada podem estar dispostos diversos serviços e comércios. Dentre as mercadorias encontra-se roupas, sapatos, acessórios de vestuário, cosméticos, maquiagens, tecidos, eletrodomésticos, móveis novos ou antigos, material de construção, utensílios domésticos, acessórios para carros ou celulares, material para festas ou escolares, assim como também serviços essenciais, como bancos. 
Todos estes estabelecimentos estão espalhados pelas ruas do bairro, estão abrigados em centenas de lojas, mas é importante salientar que a maioria das lojas tem uma pequena área física, suas fachadas são baixas. Existe também o camelódromo, que foi construído na década de 1980 para resolver o atrito entre vendedores ambulantes e lojistas (Cascudo, 1999), mesmo com o camelódromo, o Alecrim tem centenas dos chamados camelôs, vendedores que não tem registro formal em órgãos públicos. Há uma grande quantidade de vendedores pelas calçadas (tanto em quiosques ou até mesmo no chão), pelas paradas de ônibus e na praça Gentil Ferreira - popularmente conhecida como praça do relógio -, vendendo água, frutas e muitos dos artigos já citados. Não é incomum encontrar pessoas circulando pelo meio fio ou nas ruas juntos aos carros, isso porque a maioria das calçadas é estreita e desuniforme, em virtude da ocupação, com quiosques e camelôs.

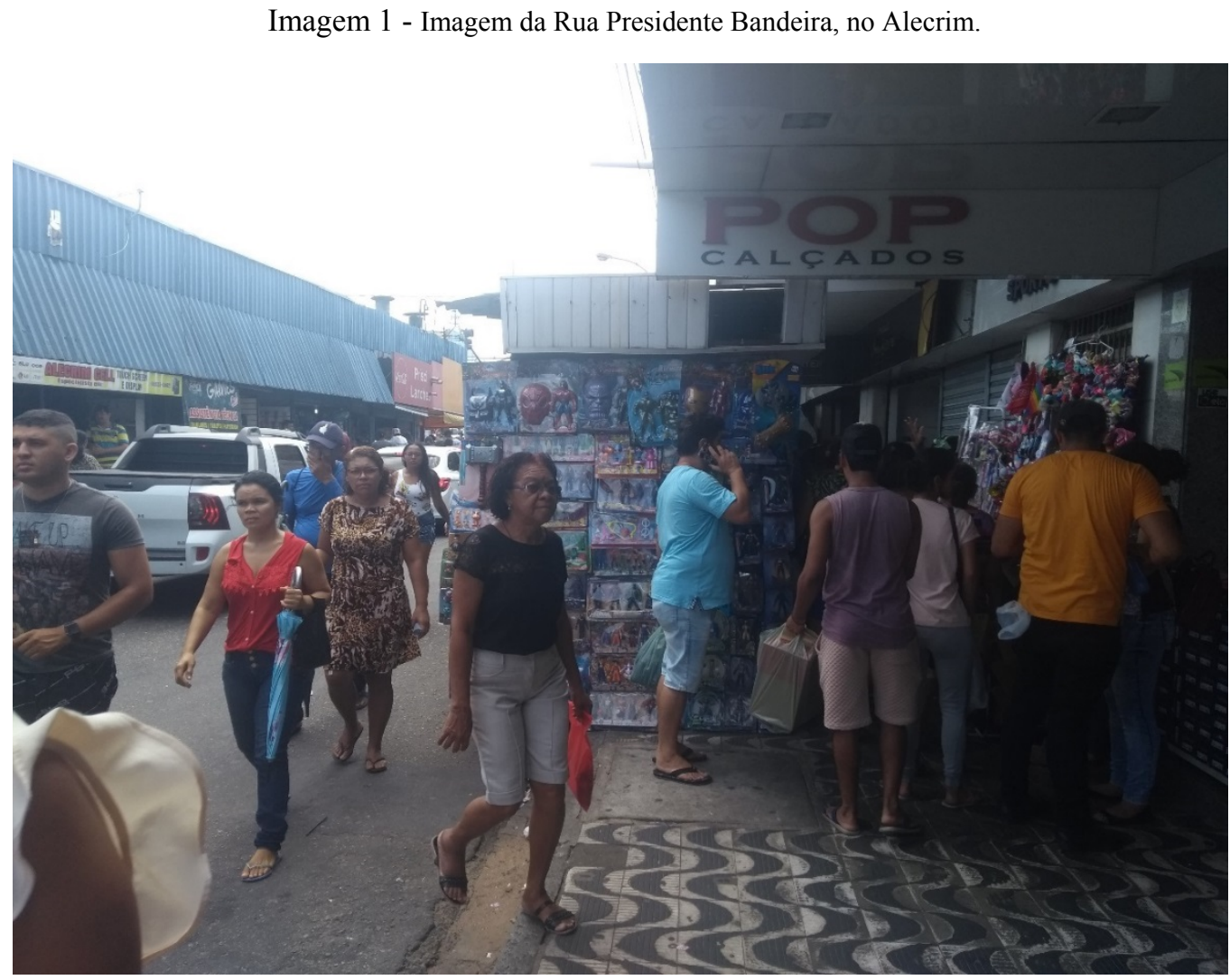

Fonte: Acervo da autora.

Uma das principais avenidas do bairro é a Presidente Bandeira, ela possui calçadas, duas faixas largas, nos dois sentidos do tráfego. Entre as duas faixas existe um canteiro central, no qual estão dispostas algumas cigarreiras, que vendem lanches e por volta das 17:30, horário em que o comercio é fechado, começam a vender espetinhos. 
Invariavelmente aos sábados acontece uma feira livre na rua Presidente Quaresma, conhecida popularmente como feira do Alecrim, esta feira vende principalmente alimentos, mas é possível também encontrar outros itens, como roupas.

O Alecrim também é conhecido por suas altas temperaturas, é considerado um local extremamente quente, no canteiro central existem algumas árvores, o mesmo não ocorre nas ruas que abrigam a maioria das lojas. Nas paradas de ônibus que não possuem coberturas, é possível ver as pessoas se agrupando em algum local de sombra próximo, como postes, para fugir do sol. Além disso, a maioria das lojas não são climatizadas, das lojas indicadas por interlocutoras a única climatizada é a loja Outlet $\mathrm{K}^{6}$.

Também existem sons que fazem parte deste espaço, buzinas de carros, carros de sons de lojas. Na maioria dos trajetos que realizei ouvi o carro do Gigantão ${ }^{7}$ das joias convidando as pessoas para comprar ou vender ouro. Em um destes trajetos circulava pelas ruas um pequeno trio elétrico, fazendo propagandas para as lojas. Há outros carros de sons pregando "a palavra de deus", como também pessoas na praça Gentil Ferreira fazendo palestra neste propósito. Dispostos pelas ruas, os próprios vendedores de lojas convidam os transeuntes a entrar nas lojas com os bordões. Existem também vendedores ambulantes de $\mathrm{Cd}$ e Dvd circulando com carrinhos de som pelas ruas, as músicas tocadas são as mais variadas, música gospel, funk, forró ou sertanejo e muitas vezes músicas da banda Grafith*. Foi interessante notar, durante caminhadas em épocas distintas, que os sons nas ruas, como também no interior das lojas se modificavam no prelúdio de datas comemorativas, isto é, na época que antecedia o carnaval era possível ouvir músicas de axé music ou marchinhas de carnaval ou antes do Natal era possível ouvir a música "Então é Natal”, de Simoni.

\section{Centro}

“O alto elevado e firme procurado por Jerônimo d'Albuquerque em dezembro de 1599 era o platô que se estende desde a praça de André d'Albuquerque... O cimo onde se construiu a primeira casa, termina, descendo no baldo" (Cascudo, 1999:143) este é o território que, de acordo com Câmara Cascudo, corresponde ao local de fundação da cidade de Natal, como também corresponde ao bairro Cidade Alta. Este bairro, é

\footnotetext{
${ }^{6}$ Esta é uma loja de roupas masculinas e femininas, localizada na Av. Presidente Bandeira.

${ }^{7}$ Esta é um loja de acessórios, localizada na Av. Presidente Bandeira.
} 
conhecido por muitos apenas como Centro, atualmente é também uma zona de comércio. No entanto, em termos de estabelecimentos, ao contrário do Alecrim, apresenta um número um pouco maior de serviços do que de comércios. De acordo com dados da Prefeitura de Natal (2006) haviam 2656 estabelecimentos, dos quais 451 eram de serviços, equivalente a 48,44\% da atividade empresarial no local e 418 estabelecimentos de comércio, equivalente a 44,9\% das atividades. Destes empreendimentos 32,22 \% eram da categoria Sem constituição, 29,32\% era Sociedade Ltda e 23,95\% Empresa individual.

Também diferente do Alecrim, no Centro há uma concentração de lojas de departamento ${ }^{8}$. Todas as lojas são climatizadas e de amplo porte, da mesma forma a loja Aliança Outlet ${ }^{9}$. Além delas existem lojas de acessórios, lojas de eletrodomésticos e móveis, utensílios para casa, quiosques (vendendo acessórios para celular, bancas de revistas ou comida), sebos de livro, armarinhos, serviços como bancos, cartórios e a prefeitura de Natal. As calçadas e paradas de ônibus do Centro também estão ocupadas por camelôs. Apesar da inicial semelhança entre os dois comércios é possível notar diferença nas edificações dos dois locais, as calçadas do Centro são mais largas. Fui até o local com fita métrica e pude constatar que algumas possuem até oito metros de largura, assim, devido a largura das calçadas há uma sensação de que os ambulantes estão mais dispersos e as calçadas mais livres, no entanto, as calçadas também não são uniformes e apresentam alguns buracos. As fachadas das lojas, seus espaços físicos e altura das construções são maiores do que no Alecrim, além disso em cima da maioria das lojas (acima das placas) é possível ver prédios antigos, exceto nas lojas de departamento. Andando pelas ruas do Centro é possível encontrar diversas árvores. $\mathrm{O}$ centro também apresenta uma outra característica que poderia ser pensada como uma vantagem natural $^{10}$, como foi mencionado o comércio está localizado em um cume, neste sentido, a altitude do espaço faz com que sua temperatura seja mais amena, em relação ao comércio do Alecrim ${ }^{11}$.

\footnotetext{
${ }^{8}$ As lojas de departamento abrangem uma variedade de produtos, como roupas, sapatos, acessórios, maquiagens, perfumes, aparelhos eletrônicos.

${ }^{9}$ Loja de roupas e acessórios, localização na Avenida Princesa Isabel.

${ }^{10}$ Termo utilizado Robert Park (1967) para pensar o espaço urbano.

${ }^{11}$ Circulando pelo Alecrim e Centro tem-se a sensação que um local é mais quente do que o outro. Esta sensação está relacionada com a arborização e altitude mais elevada no comércio do Centro. De acordo com Mendonça e Danni-Oliveira (2007) estes dois fatores interferem na temperatura. Primeiramente, a temperatura é um elemento climático, este é definido por atributos físicos que representam as propriedades da atmosfera geográfica de um determinado local. Já a altitude é um dos fatores climáticos,
} 
Imagem 2 - Avenida Rio Branco, uma das principais avenidas do comércio do Centro.

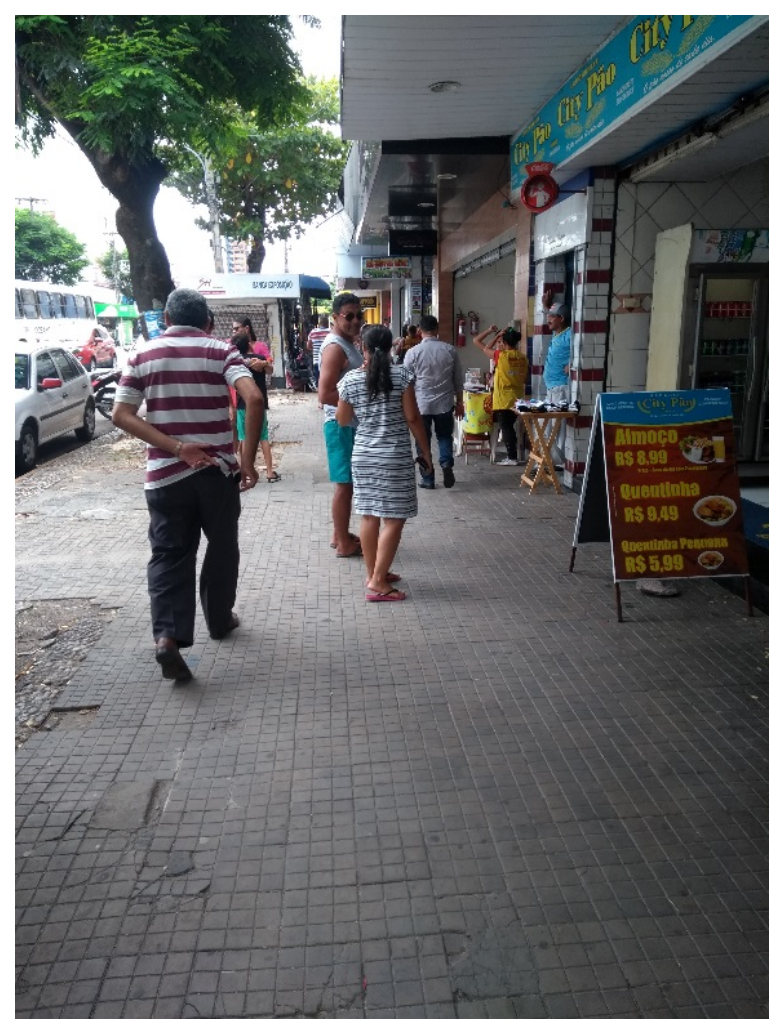

Fonte: Acervo da autora.

Como no Alecrim, os ambulantes também vendem os mais variados produtos e elaboram bordões, em uma das paradas principais em frente ao mercado é possível encontrar um vendedor com o seguinte bordão: "Olha água do amor, mata a sede e o calor", nesta mesma parada há vendedores de operadoras sempre a gritar: "Chip da oi" ou "Chip da Tim". No Centro da cidade há uma rua cheia de óticas, seus vendedores também estão sempre nas calçadas buscando convencer os transeuntes a entrar: "Tá procurando óculos hoje? Pode entrar!", do mesmo modo que o Alecrim os sons fazem parte do local.

estes são características geográficas estáticas diversificadoras da paisagem. A ação dos fatores climáticos está ligada a grande variação espacial e temporal da manifestação dos elementos climáticos, como a temperatura. Neste sentido, o relevo é um dos fatores que diversifica padrões climáticos, por causa da variação de altitude, assim, ao observar dois lugares com a mesma latitude (que também é um fator climático), mas com diferentes altitudes, o local que possuir a altitude mais elevada terá a menor temperatura, isso porque a posição do relevo pode dificultar ou favorecer os fluxos de calor e umidade.

Por último, a vegetação também desempenha um papel regulador de umidade e temperatura, em áreas florestadas as temperaturas serão menores do que em áreas com outro tipo de cobertura, já que os troncos, copas ou galhos bloqueiam a radiação solar direta, diminuindo a disposição de energia para aquecer o ar. As árvores também influem nos processos de infiltração da água no solo, devido a ação das raízes a infiltração é mais eficaz. Consequentemente há uma diminuição do escoamento, dispondo mais água para os processos de evaporação e evapotranspiração, criando um ambiente mais umidificado e com a temperatura mais baixa. 
As ruas e lojas do Centro também ficavam repletas de símbolos no prelúdio de datas comemorativas. Durante o mês de Junho, no qual ocorrem tradicionais as festas juninas, as ruas encheram-se de dois dos seus principais símbolos: as bandeirinhas e os balões. Em outra rua foi possível encontrar uma fogueira de São João com dois bonecos vestidos de roupas de quadrilha. Neste sentido, o mesmo ocorreu com os sons, foi possível observar que à medida as festas iam ocorrendo os sons nos espaços iam se modificando. No período junino havia um trio de sanfoneiros tocando músicas de forró, as lojas seguiam o mesmo ritmo, tocavam principalmente músicas de forró.

\section{Natal Shopping}

O Natal Shopping está localizado no bairro Candelária, bairro de classe média. É um espaço fechado, climatizado, com música ambiente. O shopping está dividido em dois andares, no primeiro andar, a partir da entrada principal, pela rua Salgado Filho, há uma bifurcação em dois amplos corredores, onde estão dispersas as lojas. Os corredores são bem iluminados e o seu piso é uniforme, em um material que se assemelha a cerâmica. No andar debaixo, que pode ser acessado por escadas, escadas rolantes e elevadores, estão distribuídas algumas outras lojas, a praça de alimentação, e alguns serviços. De acordo com seu próprio site, o shopping tem aproximadamente 150 lojas, praça de alimentação, cinema, academia. A maior parte das lojas são direcionadas para vestuário e beleza, mas é possível também encontrar lojas de decoração, eletrônicos, farmácias.

O ambiente é considerado elitizado, pois boa parte das lojas são classificadas como "de marca". Além das lojas, outros fatores como os preços dos restaurantes ou estacionamento pago, contribuem para a classificação deste ambiente como elitizado, também é lugar comum encontrar pessoas circulando pelo Natal Shopping com seus cachorros de raça, muito limpos e bem penteados, um contraponto aos cachorros ou gatos abandonados que circulam pelo Alecrim e Centro. 
Imagem 3 - Corredor do primeiro andar do Natal Shopping, durante a semana

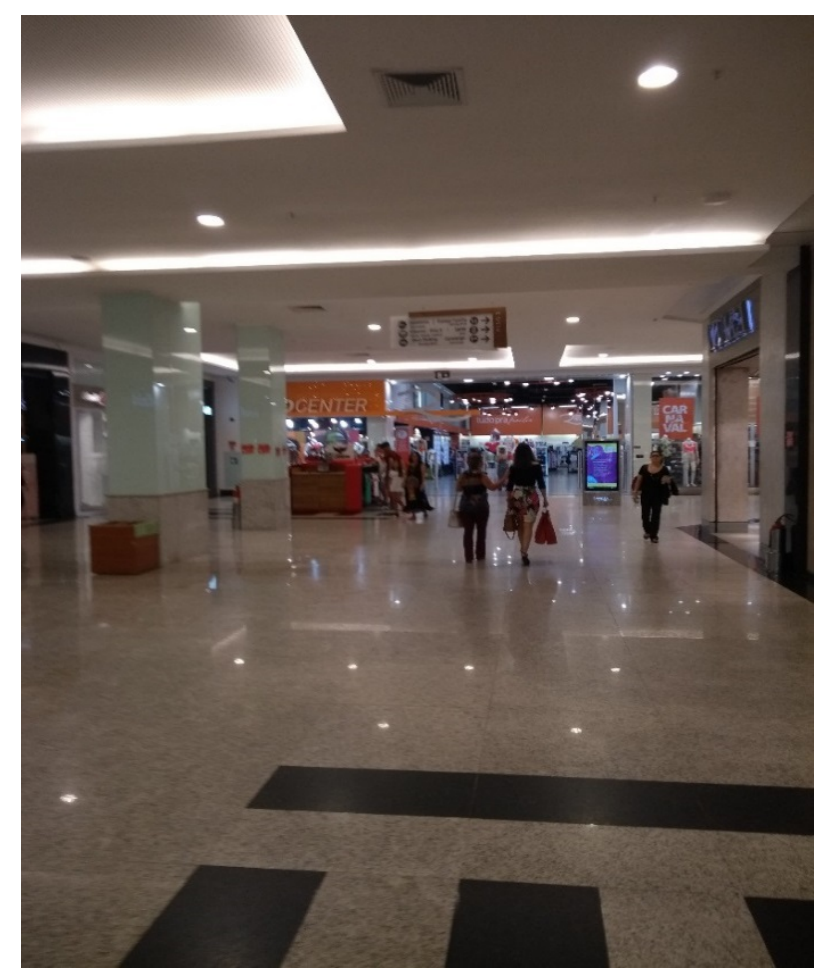

Fonte: Acervo da autora

Por vezes alguns espaços do shopping são utilizados para entretenimento: o estacionamento frontal é utilizado de modo diferente, eventualmente, ocorre uma feira de artesanato, nesta feira vende-se comidas, artesanatos e realiza-se sorteios; neste mesmo estacionamento acontecem outras atividades, como palestra e shows de atrações nacionais, alguns pagos outros gratuitos. A praça de alimentação é outro espaço utilizado para entretenimento, na época da Copa do mundo de 2018 haviam telões exibindo os jogos.

Além de todos estes espaços, em frente ao Shopping, próximo à entrada principal, existe uma passarela e em sua calçada há uma parada de ônibus, onde há um comércio informal. Na parada de ônibus são vendidas comidas, acessórios para celular, óculos, relógios, bijuterias e no período do Carnatal $^{12}$ vendiam-se cintos, acessórios para cabelos, bolsas térmicas e abadás. No período que antecede o carnaval é comum encontrar fantasias para crianças. Há um contraste de preços entre o comércio da parada e do interior do shopping, as comidas vendidas na parada e passarela tem valores mais baixos em relação à praça de alimentação.

\footnotetext{
${ }^{12}$ Festa que ocorre no mês de dezembro, durante quatro dias, em Natal.
} 
Devido aos corredores amplos é simples se locomover no Shopping, também uma sensação que ele está vazio o tempo todo, o oposto ocorre na parada e passarela. Diferente dos comércios de rua, apenas na época natalina o Natal Shopping enfeita sua fachada, corredores e instala uma grande árvore. Mesmo assim, parte das lojas disponibilizam itens de acordo com as datas comemorativas.

Podemos ver que cada um destes espaços comerciais apresenta características e aspectos que os particularizam. Inicialmente o Alecrim e Centro podem ser vistos apenas como comércios de rua semelhantes, que destoam do Natal Shopping, considerado um espaço elitizado. Todavia, se esquadrinharmos um aspecto como a temperatura, que é distinta nos três espaços, percebermos como este aspecto influi na experiência de compra das interlocutoras, esta característica uma ganha significação quando está relacionada ao uso que cada uma das interlocutoras deu a este espaço.

Neste sentido, Robert Park (1967) ao pensar a cidade propôs que esta é algo que vai além do uma avalanche de indivíduos, ruas, edifícios, construções etc, se trata de um estado de espírito, um corpo de costumes e tradições "Está envolvida nos processos vitais das pessoas que a compõem” (Park, 1967, p:25). A composição da cidade, apesar de parecer mero artefato, tem dispositivos que estão aquém do nível utilitário tornando a cidade viva, através do uso e costume. A vida e a cultura urbana são mais variadas, sutis e complicadas, sua vivacidade está nas pessoas que a habitam, as quais estabelecem uma organização moral, esta atua junto a organização física, interagindo entre si. A estrutura da cidade está pautada nos humanos, há uma necessidade de habitantes, estes habitantes são determinantes para esta estrutura e para a tradição, tais aspectos formam um complexo cultural comum que determinam o que há de característico e peculiar na cidade. Para nós este processo de interação entre os habitantes e a organização será importante para próxima seção, na qual apresentarei o relacionamento que as interlocutoras construíram com estes espaços.

\section{Como as mulheres se relacionam com os espaços}

Como exemplifiquei a temperatura é um dos aspectos que caracteriza cada espaço, mas este não é o único. Quando o Alecrim é citado, lembra-se imediatamente do calor, do barulho, preços baixos, dificuldade de locomoção (devido a quantidade de 
pessoas que circulam no local, calçadas estreitas e desuniformes) e trânsito e também de sua grande variedade, responsável por um bordão, criado pelo natalense: "Se não encontrar no Alecrim, não encontra em lugar nenhum". O Centro apresenta uma temperatura mais amena em relação ao Alecrim, devido sua arborização e altitude, além disso, neste comercio as calçadas são mais largas, apresentam lojas mais amplas em espaço físico e diversas lojas de departamento. Por último, o Natal Shopping é bastante lembrado por seus preços altos, mas por seu ambiente climatizado, silencioso.

Retomei estes aspectos pois serão pertinentes na relação das interlocutoras com os comércios, mesmo assim, é importante salientar que eles serão assimilados de forma diferentes por cada uma das interlocutoras. O que ocorre, segundo Magnani (2003), porque a rua possibilita uma infinidade de interpretações, pois pode ser além de um local de trabalho ou moradia. Ela está sujeita a diversos pontos de vista, oferecidos pela multiplicidade de usuários e suas referências culturais.

Tamires tem 32 anos, é mestranda de ciências biológicas (UFRN), mora com sua mãe no bairro Capim Macio, a cerca de $8 \mathrm{~km}$ do Alecrim. A relação de Tamires com o comércio se iniciou quando frequentava o comércio com sua mãe, porém segundo ela "era um dilema", pois não encontravam lugar para estacionar o carro e não queriam pagar estacionamento. Posteriormente, ela passou a circular pelo comércio sozinha por causa de uma loja: A Raianny Modas ${ }^{13}$. Ela conheceu a loja a partir da plataforma Instagram $^{14}$. No entanto, comprava inicialmente na unidade da loja que estava localizada em Paramirim ${ }^{15}$, mas precisava recorrer ao seu namorado para levá-la de carro, visto que não havia acesso de ônibus. Ainda pelo Instagram a loja anunciou a

\footnotetext{
${ }^{13}$ Esta é uma loja de roupa e acessórios, com diversas unidades em Natal e Parnamirim.

${ }^{14} \mathrm{O}$ Instagram pode ser instalado em celulares, o site de rede social objetiva o compartilhamento de fotos ou vídeos, além disso, o aplicativo apresenta diversas ferramentas que possibilitam interação. O usuário cria o seu perfil, a partir dele pode seguir pessoas, porém, aqui há uma relação de assimetria, os usuários não precisam seguir de volta se não desejarem. Ao compartilhar suas fotos as pessoas podem interagir através do botão curtir ou comentar. Em suas postagens é possível que os usuários atribuam legendas, as legendas permitem o uso hashtags ${ }^{14}$. Há também a ferramenta story, na qual o usuário pode compartilhar fotos ou vídeos que desaparecem em 24 horas - mas, podem ser fixadas como destaques no perfil do usuário. O story é uma ferramenta dinâmica, oferece uma gama de filtros, como de animais, corações, arco íris, entre outros, o story permite ao usuário postar vídeos ao vivo, rebobinados, compartilhar textos, realizar enquetes, perguntas ou questionários.
}

${ }^{15}$ Parnamirim é um município, que faz parte da região metropolitana da grande Natal. 
inauguração de uma outra unidade no Alecrim. Este foi o ponto de partida, a partir da descoberta desta loja Tamires passou a circular pelo Alecrim, ela relatou:

À medida que fui andando e vendo outras lojas com plaquinhas de preço baixo ia entrando. Eu tava andando, aí descobri outra lojinha, quando cheguei lá e perguntei o preço de uma blusa, a mulher respondeu que era 13 reais. Daí eu levei 3, porque eu pensei: isso daqui dá pra ir para aula. Elas são daquelas que tem alcinhas, rendinhas e uma malhinha bem boa. Pronto, em comparação com a loja da minha cunhada, ela cobra 25, lá era 13.

Dessa forma, Tamires foi conhecendo novas lojas para comprar, dentre elas as lojas Brás e Elite, lojas no Beco do Café, barraquinhas que vendem calcinha e sutiã.

O calor do comércio não passa despercebido, por isso, quando vai ao comércio opta por usar shorts, mas, dessa forma o calor não se torna um problema. Ela relatou que ao usar calça no local não se sentiu confortável, pois o calor fez com que a peça grudasse no corpo. Para ela usar short facilita experimentar roupas - é importante salientar que não são todas as lojas do Alecrim que disponibilizam provadores. Este fator limita algumas compras para Tamires, nas lojas em que não pode provar as peças ela compra apenas blusas. Devido a esta limitação compra calças jeans e shorts jeans em lojas específicas, Brás Atacado e Morena Modas, respectivamente.

Para além dos fatores variedade e preço, questionei Tamires porque ela preferia comprar no Alecrim. Ela explicou que, em primeiro lugar, pode ir ao Alecrim de ônibus sozinha, sem depender de sua mãe ou namorado para levá-la de carro, pois há uma linha direta de ônibus da sua casa até o local, em segundo lugar o Alecrim apresenta uma certa comodidade pois o ponto de ônibus é central e muito próximo das lojas.

Tamires assume que há dispêndio de tempo para ir ao local, então seleciona um dia por mês que esteja livre para "comprar tudo que tem que comprar". Devido a suas andanças pelo comércio ela já sabe aonde ir, ela explicou:

Um exemplo, quero comprar roupas de academia, aí já vou direto no Brás ou Elite, comprar blusinhas, eu adoro as blusinhas de lá, pra malhar. São bem baratinhas, que é 15,20 reais.

Por outro lado, quando questionada sobre sua relação com o Natal Shopping ela aponta o shopping como um local de passeio, como cinema e jantares, já que para ela os preços são muito elevados para compras, ela comparou o preço de calcinhas: 
Se eu for comprar no Natal Shopping uma calcinha é 25 (reais), quando eu compro numas barraquinhas ou numa loja no Beco do Café (no Alecrim) as calcinhas são 3 por 10 (reais).

Sobre o Centro, ela explicou que mesmo que o comércio seja mais ventilado ou tenha lojas de departamento, ela prefere comprar no Alecrim, pois vê a concentração de pessoas no local como um ponto positivo em termos de segurança. Além disto, o ponto de ônibus em que para uma linha que vá até sua casa é ainda mais afastado, por isso ela se sente insegura para circular no local sozinha.

Jussara também gosta de fazer compras nos comércios de rua. Ela tem 24 anos, é psicóloga, atualmente sua ocupação é de monitora no Senac, onde recebe uma bolsa, e mora com seus pais. Sua relação com o Alecrim aconteceu através da maquiagem. Ela explicou que sempre soube que os produtos do comércio tinham preços baixos, porém não gostava de ir ao Alecrim de ônibus. Ela relatou:

Sempre tive muita preguiça de ir no Alecrim, principalmente de ônibus, porque minha mãe me fazia ir muito pra comprar material escolar, e tinha que voltar com sacos e sacos e eu tinha vontade de chorar.

Ela explica que começou a frequentar o espaço por dois fatores, o primeiro deles é que ganhou um carro, e o segundo foi (segundo ela) uma explosão do Instagram e a febre de Youtubers. Através da primeira plataforma ela encontrou uma loja chamada Lili Importados ${ }^{16}$. A primeira vez que foi ao comércio sozinha, foi nesta loja e comprou, mesmo considerando que era uma loja grande (no sentido de ter muita variedade), não considerou bons os seus preços. Todavia, como já foi mencionado, o Alecrim apresenta uma grande variedade de produtos, então quando Jussara foi pela segunda vez, para comprar produtos para sua festa de aniversário, encontrou algumas lojas de maquiagem, ela contou:

Aí eu fiquei louca, minha amiga, eu fiquei louca, quando eu via pó de 10 reais e outras coisas, eu até comprei uma cartela de cílios deste tamanho (neste momento ela gesticula demonstrando o tamanho do cílio) que eu nunca nem usei, e nem tem como a pessoa usar, porque sabe aqueles duros, eu fiquei louca querendo comprar as coisas.

\footnotetext{
${ }^{16}$ Lilli Importados é uma lojas de variedades localizada no Alecrim, vende maquiagens, utensílios para casa, acessórios etc.
} 
Mesmo considerando os preços baixos e mesmo com o carro ela pondera que é necessário ter tempo livre, dessa forma só vai aos comércios quando tem o dia inteiro disponível para circular, sendo o tempo livre no caso do Alecrim ainda mais necessário devido à dificuldade para estacionar. Neste caso ou estaciona o carro distante ou paga $\mathrm{o}$ estacionamento, a opção de Jussara é por deixar o carro distante, dentro do estacionamento do Nordestão $^{17}$, e ir andando até o que ela chamou de formigueiro, que seria o ponto central, onde ficam a maioria das lojas de roupas, maquiagens e acessórios. Jussara afirmou:

Se eu for comprar em grande quantidade eu vou no Alecrim ou na Cidade, mas se eu tiver precisando muito de alguma coisa e não tiver tempo, porque é preciso ir com tempo, não dá pra ir só com 10 minutinhos lá no Alecrim, não tem condições, nesse tempo você chega, 10 minutinhos você chega no estacionamento e deixa o carro até a loja.

Para ela ir ao Alecrim não é um martírio, mas, considera necessária uma preparação psicológica para enfrentar o calor e para andar bastante. Nestas situações ela opta por uma roupa confortável como chinelo havaiana e camiseta "folgadíssima".

A grande paixão de Jussara é a maquiagem, ela explicou que já teve caixas cheias de produtos. Jussara compra roupa duas vezes por ano, em lojas de departamento, ela não gosta de comprar roupas porque tem dificuldades de encontrar seu tamanho, então sua prioridade de compras é maquiagem. Ela costuma usar maquiagem diariamente, então quando alguns produtos acabam ela repõe imediatamente. Jussara compra tais produtos, além das lojas no Alecrim, em lojas do Centro, com a Estilosa ou Espaço Dez ${ }^{18}$. Nos dois espaços é onde encontra os preços mais baixos, no entanto, algumas vezes, ela compra numa loja no Natal Shopping, chamada Lavic. Como ela explicou, para ir aos comércios demanda tempo, então quando o produto acaba, e ela não dispõe de tempo passa no shopping e mesmo pagando um valor mais alto, no mesmo produto, compra.

Brenda tem 24 anos, é mestranda em Serviço Social (UFRN) e maquiadora, mora com sua mãe e irmão, no bairro Planalto, a cerca de $9 \mathrm{~km}$ do comércio do Alecrim. Ela não julgou como uma dificuldade chegar ao local, pois costuma utilizar uma linha de ônibus que passa em frente à sua casa e vai até o comércio. No entanto, os aspectos

\footnotetext{
${ }^{17}$ Nordestão é um supermercado local.

${ }^{18}$ Lojas de bijuterias e maquiagens.
} 
como calor e dificuldade de locomoção (dentro do próprio espaço comercial) também não passaram despercebidos para Brenda, ela enfatizou:

Eu acho que ninguém gosta de ir ao Alecrim, pelo espaço do Alecrim, é muito cheio, é muito quente, difícil de encontrar as coisas por causa da referência, avenida nove 9 , avenida 8 , onde diabo é a avenida 8 ?

Porém, ela começou a aprender a circular no espaço sozinha, quando passou a receber uma bolsa, no período em que fazia graduação de Serviço Social (UFRN). Ela ia ao local em busca de materiais para artesanato "eu gosto muito de fazer minhas próprias coisas”. Mas, nem sempre foi assim! Ela explicou que existe uma brincadeira com sua irmã, pois certa vez sua mãe, que vendia salgados, pediu para ela comprar materiais e ela respondeu:

-Mãe, não vou porque não sei onde fica as lojas!

A partir deste momento sua irmã passou a pilheria-la, questionando sempre que vai ao Alecrim:

-Ah, então você já aprendeu onde ficam as lojas?

Ela explicou que de tanto ir ao local aprendeu a se guiar, aprendendo os lados:

Esse lado é mais pra festa, esse lado é mais pra roupa.

Outra tática que Brenda adotou atualmente é ver o Instagram para encontrar lojas específicas, antes de ir ao local. Além de materiais para artesanato ela costuma comprar o que chamou de "futilidadeszinhas pequenininhas" ${ }^{19}$.Porém, Brenda não costuma comprar roupas no Alecrim, por dificuldades para encontrar seu tamanho, somente em uma ocasião encontrou uma loja chinesa que vendia roupas de tamanhos variados, as roupas coincidiam com o seu tamanho, porém, enfatizou não atendia a tamanhos maiores que o dela:

Mas, no Alecrim é praticamente impossível porque é barato, mas é tudo tamanho único ou quando me mostram uma (tamanho) G nunca dá em mim, dá em tu eu acho (falou se referindo a mim), é pequeno demais.

Devido a esta dificuldade de encontrar peças do seu tamanho ela recorre a algumas lojas de departamento, localizadas no comércio do Centro, para comprar suas roupas. Para ela, também não há dificuldade de chegar até o local de ônibus e ela considera mais fácil circular pelo local:

\footnotetext{
${ }^{19}$ Brenda definiu como "futilidadeszinhas pequenininhas" acessórios, bijuterias em geral, maquiagens, até mesmo sua aliança (ela é noiva) comprou no Alecrim.
} 
É muito mais fácil andar lá, mais tranquilo.

Porém, Brenda não compra na maioria das lojas, ela explicou que dentro do seu conhecimento só havia quatro possibilidades de lojas para comprar:

Eu sei que a Riachuelo tem uma seção muito pequena de tamanhos grandes, então, eu não perco meu tempo indo lá, só as vezes em último caso que eu vou. Na Leader tem uma seção tamanho Plus (size) e a Marisa. Tem uma quarta loja, é a Cabide, que tem uma versão especificamente, mas apesar de se nomear plus size, não são tão grandes, é um plus size mediano e acaba que não me serve. Também os preços não são nenhum pouco acessíveis, então eu não vou lá. Basicamente, meio que restam a Leader e a Marisa.

Mesmo conhecendo lojas em que encontra peças para o seu tamanho ela ressaltou que os preços são mais altos do que gostaria de pagar, muitas vezes encontra peças, básicas como camisetas por 80 reais ou vestidos por 120 reais, um preço mais alto comparado a peças que não são do tamanho plus sizes ${ }^{20}$ nas lojas. Por último, ela explicou que não costuma comprar no Natal Shopping:

Assim, justamente porque tem todo um status e as lojas lá na verdade são meio caras, né?! Tá fora do meu alcance econômico.

Porém, diversas vezes durante a graduação, principalmente no período que estava escrevendo a monografia, entrava diversas vezes no shopping para desopilar, andar pelo espaço ou ir ao cinema.

Vimos até agora que, mesmo de maneiras distintas, as interlocutoras assimilaram as características dos comércios do Alecrim e Centro, e se relacionaram com estes, considerando desvantajoso comprar no Natal Shopping devido aos preços. Contudo, nem todas as interlocutoras se relacionam com os espaços desta forma. Celina tem 52 anos, mora com seu marido e filho, também no bairro Satélite. Ela tem carro e é aposentada, com seu salário costuma comprar itens de vestuário e itens para casa. Ela afirma que em relação a roupas compra em locais variados, mas sobre comprar no Alecrim e Centro, ela afirmou:

Eu detesto, porque ali é horrível pra estacionar o carro e ultimamente eu só tô andando de carro, aí fica muito ruim.

Assim, novamente a dificuldade de estacionar aparece, mas agora com uma contação diferente. $\mathrm{O}$ fator dificuldade de estacionar que não impediu Jussara, que opta por estacionar longe, para Celina é um empecilho, do mesmo modo que o calor.

\footnotetext{
${ }^{20}$ De forma simplificada, plus size é o termo atribuído a tamanhos de roupas grandes.
} 
Além disso, ela explicou que hoje em dia pensa na qualidade dos produtos e para ela estes comércios não oferecem produtos de qualidade, devido aos preços baixos. Neste sentido, Celina muitas vezes compra no Natal Shopping. Ela também costuma utilizar o espaço para lazer, como ir ao cinema como seu marido. A maioria de suas compras no shopping hoje são em lojas de sapatos e bolsas, como Carmem Sttefens e Arezzo $^{21}$. Ela explica que dá preferência a estas lojas por causa da qualidade e beleza dos itens:

Com a idade a gente procura comprar uma coisa melhor, por exemplo, a Carmem Steffens. Não é nem só pela questão da marca, é porque realmente as coisas são boas, você compra uma bolsa, uma coisa que dura. Mas, quando eu era mais nova, o negócio era variar.

Ela também ponderou sobre quando era mais jovem e não tinha um emprego que a proporcionasse comprar itens com maior qualidade:

Aí eu via só a beleza, hoje em dia eu vejo muito assim, a questão da qualidade, mas eu sou muito eclética eu digo que eu gosto da lata ao ouro.

Ela reforçou que não usa apenas itens de marcas caras, contudo, acredita que é melhor investir em itens duradouros, então, para ela não importava o valor se gostasse de um item:

Porque não adianta as vezes você compra uma bolsa (barata) e o barato sai caro, de repente se estraga, mas se eu gostar muito (de uma peça barata) eu compro e se estragar depois eu compro outra. Eu gostando, eu pago, o pior é isso, porque em conjunto de bolsa e sapato eu já paguei 1800 (reais) na Carmem Steffens.

Neide e Cibelle também costumam comprar no Natal Shopping. As duas são mãe e filha, tem 54 e 25 anos, respectivamente, moram no bairro Satélite. Neide é aposentada, porém, ainda trabalha em uma escola e Cibelle é graduanda em Serviço Social (UFRN). Elas costumam ir juntas ao Natal Shopping, algumas vezes se encontram quando Neide sai do trabalho e Cibelle da universidade. Nestas ocasiões elas comem no Sal e Brasa Grill e circulam pelas lojas, em busca de promoções. Uma das lojas que elas mais compram é a Renner, as duas concordaram que a unidade do Natal Shopping é melhor para comprar roupas, enquanto a unidade do Midway Mall ${ }^{22}$ é melhor para comprar sapatos. Neide afirmou:

A variedade das roupas de lá (Renner, unidade Natal Shopping) é muito melhor, as roupas de lá são melhores e eles botam em promoção, coisa que na outra não tem (Renner, unidade Midway Mall).

\footnotetext{
${ }^{21}$ Lojas de sapatos e bolsas.

${ }^{22}$ Se trata de outro shopping de Natal.
} 
Mas, estes não são os únicos itens que elas costumam olhar e comprar na loja. Cibelle relatou:

Eu gosto muito da Renner, muitas peças de roupa e sapatos de lá me chamam atenção e até bijuterias, porque as vezes o design das peças de lá, são designs que eu procuro, que eu gosto, mas não encontro no Alecrim, de jeito nenhum, eu já conheço as lojas de bijuteria lá e nunca acho. Então, as vezes eu levo.

Além desta loja, elas relataram que compram em lojas de sapatos, como Sonho dos pés, Mania de Couro, Vila Lara e Esposende. As últimas duas vezes que foram ao Natal Shopping encontraram sapatos que agradou as duas, por isso compraram dois pares de sapatos iguais. Um deles foi um tamanco que custou vinte reais, na loja Mania de Couro. O segundo par foi na Sonho dos Pés, custou quarenta reais, Neide explicou:

Toda vida que eu vou no Natal Shopping, dou uma olhadinha lá, pra ver se tá em promoção. Porque as sandálias de lá além de serem bonitas o material é muito bom. Eu falei a Cibelle que ia comprar, ela achou tão bonita que comprou uma pra ela.

Cibelle complementou: O design era bonito! Tinha uma nude e mainha pediu pra ver a dourada, mas eu achava que a dourada ia ser feia. Só que quando eu vi, pensei: Adorei esta sandália! Vou querer uma também e passei o ano novo com ela. $\mathrm{O}$ design é bonito, é confortável, mas ao mesmo tempo tem uma cara de praia e de rica.

Cibelle também comparou esta sandália a uma outra que estava em promoção, por oitenta reais, na loja Esposende, para elas a qualidade não era boa:

Parecia que eu ia usar duas vezes e ia se torar. Quando vou comprar também levo em consideração a qualidade, porque quero fazer uma compra inteligente.

Mesmo gostando de comprar no Natal Shopping, as duas costumam comprar no Alecrim. Neide trabalhou durante anos em uma loja de automotivos no comércio. Ela costumava circular pelo espaço após o fim do expediente. Desta forma Neide fez um mapeamento de onde se localizavam as lojas. Tal fato facilitou tanto suas compras, quanto as compras de Cibelle. Neide afirmou:

Eu gosto muito de andar no Alecrim, porque no Alecrim a gente encontra tudo que você quiser, tudo! Tudo! O que você imaginar encontrar no Alecrim, a variedade é muito boa e os preços também. Uma coisa boa do Alecrim agora, é que tem umas lojas com peças de qualidade ${ }^{23}$, porque antigamente não tinha, né?!

Já Cibelle, inicialmente ia sempre acompanhada de Neide, tanto porque esta era seu guia, quanto pelo fato de depender totalmente, na época, em termos financeiros. Com o tempo, aprendeu a circular sozinha pelo local por já conhecer as lojas. No sentido do dinheiro, atualmente recebe uma bolsa e mesmo antes disso juntava o dinheiro que os pais ou tios davam para comprar suas coisas. Mesmo assumindo que o

\footnotetext{
${ }^{23}$ As peças que Neide estava se referindo eram roupas e utensílios para casa.
} 
Alecrim suga suas energias, por causa do calor, Cibelle costuma comprar bastante no local. Ela consome os mais variados itens, roupas, acessórios, maquiagens, produtos pra cabelo, considera que consegue fazer boas compras, encontrando uma variedade de itens de qualidade, com preços baixos. Ela e sua mãe frequentam pouco o Centro, por considerarem os preços um pouco mais altos.

Os três locais de comércios apresentam uma gama de lojas, com preços, itens variados e características que os particularizam. Estas características criam uma impressão inicial, que faz com algumas mulheres, evitem comprar no espaço por acreditar que devido a estes fatores não conseguirão fazer uma boa compra. Vimos situações em que devido ao calor, a dificuldade estacionar ou mesmo o preço elevado, impedisse que a mulher voltasse a querer comprar naquele espaço, como o caso de Celina. No entanto, em outras situações podemos perceber que a assiduidade fez com que as mulheres pudessem se familiarizar com os espaços e com a configuração destes, elaborando estratégias de circulação e compras.

Então, a relação criada por cada mulher com o espaço pode variar. Por exemplo, o ponto que é positivo pra Brenda, como a facilidade de circular no Centro é um fator negativo para Tamires. A priori, pode-se pensar que o Natal Shopping, por ser um espaço fechado, que concentra as lojas, seja mais fácil comprar, o Alecrim seja o mais difícil, devido a quantidade de lojas pequenas e dispersas e o Centro, seja intermediário, devido a suas construções mais amplas. Contudo, o nível de facilidade para comprar em um espaço ou outro, é determinado pela familiaridade com o espaço e com o conceito do que é uma boa compra.

Neste sentido, o conhecimento é imprescindível para que as interlocutoras conseguissem realizar boas compras, ou seja, elas fizeram um mapeamento das lojas em cada espaço, baseado em seu gosto pessoal, comparando preços e qualidade do produto. Novamente, isto ocorre porque o consumo não se trata apenas de uma troca monetária, mas é criador de relações sociais. O consumo está ligado a um ciclo, na minha primeira parte temos o planejamento das compras, na segunda, o próprio ato da compra e por último, o uso dos itens. O planejamento, interfere diretamente no ato em si da compra, é neste sentido, que o conhecimento é relevante.

Conforme Daniel Miller (2002) comprar é uma experiência, para ele a atividade mais importante da compra é o poupar, o ato de comprar é uma habilidade. Neste caso, 
o poupar não quer dizer necessariamente gastar menos dinheiro, será um fim em si mesmo, a busca por preços baixos é baseada numa comparação sistemática. $\mathrm{O}$ fato de existir uma grande variedade de produtos é que também existe uma diversidade de compradores, cada um deles utiliza de diferentes equações para economizar. Esta comparação pode ser feita através de promoções, maior aproveitamento do produto, economia através da quantidade, como também através da qualidade "Ou economizaram comprando um artigo maior, ou um artigo de marca própria/marca econômica, ou compraram o artigo mais caro por ser de melhor qualidade, e isso representa mais economia, ou mesmo um artigo menor para que o excedente não seja desperdiçado" (Miller, 2002: 67). Desta forma, o consumidor pode legitimar para si mesmo a sua escolha justificando ter feito uma economia, para isso os consumidores precisam ter um conhecimento adquirido nas experiências de compras.

Neste sentido, foi possível perceber que a definição de boa compra pode variar de acordo com as prioridades de cada uma das compradoras. Mesmo assim, todas realizavam uma comparação sistemática que está ligada a estratégias das mulheres para realizar boas compras. A comparação pode ser feita de diversas formas, algumas delas tinham um "teto de preços" e uma hierarquização de itens, isto é, estabeleciam um valor máximo que pagariam em um item e estes valores variavam de acordo com a importância que estabeleciam para a composição do seu guarda roupa, de acordo com o poder aquisitivo e disponibilidade dos itens nas lojas.

Por exemplo, Neide estabeleceu que 100 reais é valor máximo que pagaria em um item, mesmo assim, sempre busca comprar em liquidações para pagar o menor valor possível. Em contrapartida, Celina não se importa com o valor, desde que tenha qualidade, para ela este fator está ligado a marca e a durabilidade do item. Isso, porque de acordo com a sua experiência, quando era mais jovem, comprava itens mais baratos, mas estes não possuíam durabilidade.

Já Brenda também alegou dificuldade para encontrar roupas do seu tamanho e estilo. As lojas que vendem roupas plus size tem um preço elevado. Nas lojas de departamento no setor feminino não encontra roupas para o seu tamanho, ela explica que a padronagem GG da sessão feminina atende a pessoas que não são gordas, mas estão um pouco acima de magrinha, até no máximo 48. Ela explicou que 80 a 100 reais é um valor que considera alto para uma blusa, 120 reais em um vestido, mas está 
acostumada a pagar este preço. Por isso, muitas vezes ela paga este valor porque não encontra outras opções com preços mais baixos. Mesmo assim, em busca da economia Brenda adota a estratégia de comprar alguns itens possíveis, como camisetas, na ala masculina.

Não estou buscando aqui analisar situação a situação, mas estas servem para ilustrar como é a partir do conhecimento que as mulheres puderam comparar sistematicamente e estabelecer qual o melhor local para realizar suas compras. Como vimos, Jussara, Brenda e Tamires afirmaram que não costumavam comprar no Alecrim, até que (mesmo que por motivações diferentes) resolveram circular pelo comércio, desenvolveram uma relação com o espaço e puderam perceber em quais lojas poderiam comprar. À medida que elas começaram a circular e fizeram um mapeamento das lojas, elas criaram um vínculo com o local e sua percepção inicial foi modificada, de modo que consideram o Alecrim como um bom local para fazer compras e não apenas um aglomerado de lojas quente e barulhento.

Concomitantemente, a impressão inicial das interlocutoras que não estabeleceram vínculo, no sentido das compras, com o Natal Shopping é a de que o local dispõe apenas de lojas caras e "de marca", por isso frequentam o espaço apenas para lazer, nem sequer entrando nas lojas. Ora, não estou dizendo que o espaço não apresenta muitas lojas que vendem peças de altos valores, se compararmos com os comércios do Centro e Alecrim. Todavia, esta impressão inicial pode ser desmitificada analisando as compras de Cibelle e Neide. As duas, através da comparação sistemática puderam estabelecer o espaço como um bom lugar para comprar itens que não são necessariamente "de marca". Por fim, podemos concluir que para fazer suas compras, estas mulheres precisaram estabelecer um contato com os espaços comerciais e desenvolver uma relação positiva ou não com estes, ou seja, estas mulheres precisaram experienciar os espaços da cidade e as compras simultaneamente, como um processo conjunto. 


\section{REFERÊNCIAS}

CASCUDO, Câmara. Historia da cidade do Natal. Natal, IHG, 1999.

DOUGLAS, Mary e ISHERWOOD, Baron. O mundo dos bens - Para uma antropologia do consumo. Rio de Janeiro: Editora UFRJ, 1996.

DURHAM, Eunice. A pesquisa antropológica com populações urbanas: problemas e perspectivas. In: Ruth Cardoso (org) A aventura antropológica, teoria e pesquisa. Rio de Janeiro, Paz e Terra, 1986.

ECKERT, Cornélia e ROCHA, Ana Luiza C. Aventuras antropológicas nas cidades brasileiras: na trilha das trajetórias acadêmicas das antropólogas "urbanas" Eunice Durham e Ruth Cardoso. Sociabilidades Urbanas - Revista de Antropologia e Sociologia, v.1, n.3, p. 39-56, novembro de 2017. ISSN 2526-4702.

MAGNANI, José Guilherme Cantor; TORRES, Lilian Lucca (org). Na metrópole: textos de antropologia urbana. 3. ed. São Paulo: Edusp FAPESP, 2008. 318 p. ISBN: 9788531403569.

MAGNANI, José G. C. A rua e a evolução da sociabilidade; O lazer na cidade. Os urbanitas: revista digital de antropologia urbana, 0 (1). Ano 1. Outubro de 2003.

MAGNANI, José Guilherme Cantor. Etnografia como prática e experiência. Horizontes antropológicos, Porto Alegre, v. 15, n. 32, Dec. 2009.

MAGNANI, José Guilherme Cantor. De perto e de dentro: notas para uma etnografia urbana. Rev. bras. Ci. Soc. [online]. 2002, vol.17, n.49, pp.11-29.

MENDONÇA, Francisco e DANNI-OLIVEIRA, Inês M. Climatologia noções básicas e climas no Brasil. São Paulo, Oficina de Textos, 2007

MILLER, Daniel. Teoria das compras. São Paulo: Nobel, 2002

PARK, Robert E. A cidade: sugestões para investigação do comportamento humano no meio urbano (1916) in: Velho, Gilberto (org) O Fenômeno Urbano. Rio de Janeiro, Zahar, 1967.

\section{Outras referências}

Conheça mais sobre o shopping. Natal Shopping. Disponível em: < https://www.natalshopping.com.br/card/Sobreoshopping >. Acesso em: 20 de junho de 2019.

PREFEITURA DO NATAL - SEMURB. Conheça melhor o seu bairro: Alecrim. Disponível em: 
https://www.google.com/search?q=conhe $\% \mathrm{C} 3 \% \mathrm{~A} 7 \mathrm{a}+$ melhor + seu + bairro+alecrim\&oq $=$ conhe $\% \mathrm{C} 3 \% \mathrm{~A} 7 \mathrm{a}+$ melhor + seu + bairro + alecrim $+\& a q s=$ chrome..69i57j33.17018j0j9\&cli ent $=$ ms-android-samsung-ga-rev1\&sourceid=chrome-mobile\&ie=UTF-8 $>$. Acesso em 1 de janeiro de 2020.

PREFEITURA DO NATAL - SEMURB. Conheça melhor o seu bairro: Cidade Alta. < https://www.google.com/search?client=ms-android-samsung-ga-

rev1\&sxsrf=ALeKk01PkINMHWq0NFGYAx6FhXjACpwt_g\%3A1590977135456\&ei $=$ b2LUXqC5G5TF5OUPyo-

PmAE\&q $=$ conhe $\% \mathrm{C} 3 \% \mathrm{~A} 7 \mathrm{a}+$ melhor + seu + bairro + cidade + alta\&oq $=$ conhe $\% \mathrm{C} 3 \% \mathrm{~A} 7 \mathrm{a}+\mathrm{m}$ elhor+seu+bairro+cidade+alta\&gs lcp=ChNtb2JpbGUtZ3dzLXdpeilzZXJwEAMyBQg hEKABOgQIIxAnOgUIABDLAToGCAAQFhAeOgcIIRAKEKABOgQIIRAVULGbD 1j_wQ9gqMcPaABwAHgCgAHBBIgBsymSAQwwLjEwLjMuMi4yLjKYAQCgAQE \&sclient=mobile-gws-wiz-serp $>$. Acesso em: 15 de janeiro de 2020.

Recebido: $31 / 05 / 2020$

Aprovado: $04 / 09 / 2020$ 